\title{
Implementation of Digital Systems for Investment Projects and Risks Managing
}

\author{
Yana Krukhmaleva \\ Independent Scholar, Russia
}

doi: https://doi.org/10.21467/abstracts.93.101

\begin{abstract}
A BST RA C T
All global projects, without exception, carried out using modern methods and best practices of project management do not fit into the budget and deadlines. The main reason is the inability to make risk-based decisions and own the situation in the face of uncertainty, incompleteness and inaccuracy of information, in ineffective risk management. For more than 10 years, oil and gas companies have been creating complex project management information systems, the main task of which was to increase efficiency in decisionmaking under conditions of uncertainty and opacity in the implementation of international investment projects. The specifics of this type of investment is such that the assessment of profit and costs is carried out taking into account the distribution of risk between participants implementing the investment project. Risk management begins at the stage of justifying investments and is a necessary obligation under international law. In this case, we are faced with a variety of approaches, intercultural barriers and increasing
\end{abstract} levels of uncertainty.

The lack of statistical databases for the most part of the risk categories leads to the need to attract experts to analyze the degree of uncertainty. What increases the level of subjectivity of forecasts, and, as a result, the quality of project management? It should be noted that when using more complex mathematical models and technological algorithms, the subjectivity of expert assessments globally increases the subjectivity of the results of risk analysis and, thereby, reduces the effectiveness of managerial decisions. Obviously, the complexity of the system leads to a number of completely unpredictable effects. In accordance with the Federal Law of July 19, 2018 No. 209-FZ on Amendments to the Federal Law "On Joint-Stock Companies" in a public company, risk management and internal audit should be organized... This has increased the significance of the presence of risk management in state-owned corporations. But due to the lack of specifics about the formalization of this functionality, the absence of exclusively Russian risk management standards that will allow you to effectively manage projects taking into account risks in economically unstable Russian reality, the absence of criteria for evaluating the performance of the respective unit, risk management activities are formal, and efficiency is negligible in almost all large corporations. As for the use of an automated risk management solution, due to the lack of strict requirements for using a single Russian software product for risk accounting and control, most even very large companies use primitive unsuitable tools for system work. Although in this direction, Russian analogues of high-quality software already exist. Automation of projects and project risks management processes in large companies is long-term and requires solving a number of tasks:

- building a competence center within the company, developing methodological, regulatory and regulatory documentation that takes into account the requirements of international standards;

- a systematic increase in the level of company maturity in a risk-based approach to project management;

- creation of conditions for the development of the company's knowledge base in critical areas: engineering, design and technological preparation of production, production, logistics support, interaction with suppliers, project portfolio value management; - introduction of domestic (Russian) automated tools for qualitative and quantitative risk analysis, as well as for supporting risk management processes as part of an

(C) 2020 Copyright held by the author(s). Published by AIJR Publisher in "Abstracts of The Second Eurasian RISK-2020 Conference and Symposium" April 12- 19, 2020, Tbilisi, Georgia. Jointly organized by AMIR Technical Services LLC, Georgian Technical University, Institute of Geography (Kazakhstan) and Russian Institute of Petroleum Geology and Geophysics.

AijR DOI: $10.21467 /$ abstracts. 93 
The Second Eurasian RISK-2020 Conference and Symposium

integrated project and project risk management system;- comprehensive integration with the existing company system; - continuous development of the system using the latest technological solutions.

Decree of the Government of the Russian Federation of November 16, 2015 No. 1236 "On the establishment of a ban on the admission of software originating from foreign states for the purpose of procurement to meet state and municipal needs" prohibits the admission of programs originating in foreign states. In accordance with the directive of A. Siluanov, state-owned companies must convene a board of directors ten days after its receipt, where state representatives must approve the directive. After this, stateowned companies must approve a plan for the transition to Russian software within two months - by 2021, its share should exceed $50 \%$. Similar tasks should be assigned to subsidiaries. We are talking about companies from the list of No. 91-r, approved by the government in 2003. But the whole problem is that in Russia there are no analogues of imported software in many areas of activity. And plans for the transition to Russian software will not solve the problem itself. After a long search for software solutions in the field of risk management, a Russian software product was found that includes all the necessary elements for conducting a qualitative risk analysis. There are following advantages of this solution:

- a significant reduction in the cost of implementing the system and technical support;

- adapted design of algorithms for the conditions of Russian realities;

- simplification of the configuration package and "painless" integration into the company's business processes;

- the ability to deploy the system on the servers of the Customer, which ensures the protection of information;

- the absence of the need for specialized staff competencies for teamwork with risk analysis;

- the developer proposes to develop the product functionally under the requirements of the Customer. The first additional function that was included in the program was the use of the Kendall Concordance Coefficient (Multiple Rank Correlation Coefficient), which helps to identify the degree of agreement between experts. This method helps to level the subjectivity of expert opinions. Also considered options for the integration of many functional elements, using artificial intelligence, in order to reduce the degree of impact of the human factor. Researchers Amos Tversky and Daniel Kaneman (in 2002 became the Nobel laureate in economics) as far back as 1979 showed that the market depends on investor behavior, often irrational no less than fundamental factors. People often think that they act rationally and make decisions based on logic and facts. But scientists argue that this is not so. Rather, the opposite is true - people systematically make the same mistakes because of the perceptual characteristics that psychologists called cognitive distortions. There are many studies on the subject of forecasting quality. Philip Tetlock, a political scientist who has been improving the accuracy of forecasts for more than 20 years, conducted a study commissioned by the Intelligence Advanced Research Agency (IARPA, USA) and discovered a unique thing. While the quality of predictions of professional experts from politics and economics is often very low, there are high-class forecasters among ordinary people. The level of their forecasts is $78 \%$ better than that of the control group, and 30-70\% better than that of professional analysts. Scientists all over the world agree that the dynamics of economic development is fractal in nature. Fractality is also observed in the structures of large corporations. If we assume that companies, corporations, states are the same fractal systems, and the mental elements are inherent in the elements of the systems, as well as the entire system as a whole. This phenomenon also applies to Western systems. The question arises: how applicable technologies, software systems and standards created in countries with stable economies in Russian companies?! 